\title{
Erratum to: Asking questions of (what) assessment (should do) for learning: the case of bite-sized assessment for learning in Singapore
}

\author{
Kelvin Heng Kiat Tan ${ }^{1}$
}

Published online: 24 December 2016

C) Springer Science+Business Media Dordrecht 2016

\section{Erratum to: Educ Res Policy Prac DOI 10.1007/s10671-016-9196-5}

In the above-mentioned article, the given name and family name of the author has been published incorrectly in the online first publication. This is the correct version: the author's surname is Tan, the first name is Kelvin, and the middle name is Heng Kiat. The article should be cited as Tan, K.H.K. This will be rectified in the final published version.

In the second last paragraph on the 3rd page (above the Header " 3 The problem of AfL being introduced a slogan") is the sentence "Such a scenario reveals insights into how AfL implementation may result in unintended and undesirable (undersirable?) consequences."

This sentence will be corrected in the final published version as "Such a scenario reveals insights into how AfL implementation may result in unintended and undesirable consequences."

Our apologies for the errors.

The online version of the original article can be found under doi:10.1007/s10671-016-9196-5.

Kelvin Heng Kiat Tan

kelvin.tan@nie.edu.sg

1 Curriculum, Teaching and Learning Department, National Institute of Education,

1 Nanyang Walk, Singapore 637616, Singapore 